\title{
A DISCRIMINAÇAO ENQUANTO ELEMENTO DEFINIDOR DA MINORIA NEGRA EM TERRITÓRIO BRASILEIRO
}

\author{
Fernanda Estanislau Alves Pereira ${ }^{1}$ \\ Raquel Coelho de Freitas ${ }^{2}$
}

Resumo: A pesquisa propõe uma nova conceituação do grupo minoritário de negros em território brasileiro. A reflexão profunda de todos os discursos oficiais acerca da harmonia racial ou políticas públicas voltadas aos negros, aponta para a inadequação de conceituações com delimitação de raça em aspectos fechados e biológicos. A inadequação de um conceito de raça influencia diretamente no atual fracasso das políticas públicas brasileiras voltadas ao combate à discriminação.

Palavras-chave: Racismo; Raça; Negros; Minorias; Direito das minorias; Discriminação.

\section{THE DISCRIMINATION AS A DEFINING ELEMENT OF BLACK MINORITY IN BRAZILIAN TERRITORY.}

\begin{abstract}
The research proposes a new conceptualization of the minority group of blacks in Brazilian territory. The deep reflection of all official discourses about racial harmony or public policies directed at black minority points to the inadequacy of conceptualizations with the delimitation of race in a closed and biological aspect. The inadequacy of a race concept directly influences the current failure of Brazilian anti-discrimination policies.
\end{abstract}

Keywords: Racism; Breed; Black minority; Minorities; Minority rights; discrimination.

\footnotetext{
${ }^{1}$ Mestranda em Direito Constitucional pela Faculdade de Direito da Universidade Federal do Ceará (UFC) e Advogada. Endereço postal: Av. barão de studart, 2765, ap. 602, bairro Dionísio Torres cep 60120-002, Fortaleza-CE. Endereço eletrônico: fernandaeap@gmail.com.

${ }^{2}$ Doutora em Direito Público pela Universidade do Estado do Rio de janeiro (UERJ) e Professora do Programa de Pós-graduação da Faculdade de Direito da Universidade Federal do Ceará (UFC). Endereço postal: Av. Rui Barbosa, 2111, apt. 201, bairro Joaquim Távora, cep 60115-222, Fortaleza-CE. Endereço eletrônico: rclcesar@gmail.com.
} 


\section{INTRODUÇÃO}

As minorias começam a ter o reconhecimento da necessidade de proteção e medidas que implicam uma postura ativa dos governos estatais desde o contexto da primeira guerra mundial. A falta de representação política e ausência de componentes desses grupos nas tomadas de decisões políticas não pode ser, afinal, encarada como casual e espontânea. As histórias e as culturas contribuem para manutenção ativa dessas hierarquizações e exclusões que ocorrem, em relação aos grupos minoritários, de forma sistemática.

A preocupação em relação aos gastos e medidas públicas deve ser natural em toda sociedade, e o envolvimento do Estado nas demandas sociais deve implicar necessariamente em situações que contribuam para a própria razão de ser de um Estado democrático e beneficiem não apenas os indivíduos envolvidos em conflitos pontuais, mas, em diferentes medidas, todos os cidadãos.

As mudanças sociais implicam, geralmente, em quebrar eventos e posturas que seguem se repetindo há gerações; eventos que representam um comportamento que pode ser interpretado como natural, o comportamento que é visto na maioria das pessoas que os circundam. Nussbaum (2015) atenta para a importância da voz dissidente e a tendência humana de adotar posturas nocivas a outros humanos, desde que se identifique como grupo diferente, encontre legitimidade intelectual para a crença nessa diferença e que esteja rodeado em coletivo que age dessa maneira.

Dessa forma, pode-se constatar que as mudanças sociais serão significativamente desconfortáveis para aqueles que ocupam posições privilegiadas na hierarquia social, e somando à uma ideia de eficácia finalística em relação à minoria protegida, a definição dos grupos minoritários também justifica e facilita a aceitação social de uma postura ativa dos Estados, ao promoverem a igualdade de oportunidades e uma integração social que conserve as identidades diferentes.

Em 1922, a ONU aprovou a Declaração sobre os direitos das pessoas pertencentes a minorias nacionais ou étnicas, religiosas e linguísticas, reafirmando a importância da proteção desses grupos, por parte dos Estados e de organizações não- governamentais, em caráter local e também em caráter global: o que o relatório traz enquanto um "fortalecimento da amizade e cooperação entre pessoas e Estados" (THORNBERRY, 1991, p.4). No entanto, apenas após a segunda guerra mundial que o direito de minorias e o combate à discriminação passou a integrar de forma mais objetiva as agendas políticas internacionais; nas quais destacam-se o Pacto 
Internacional dos Direitos Civis e Políticos (PIDCP) e do Pacto Internacional sobre Direitos Econômicos, Sociais e Culturais (PIDESC), ambos em 1966, pela ONU.

Em relação aos negros em território brasileiro, tivemos a política de cotas implementada no governo FHC (presidente Fernando Henrique Cardoso) e fortalecidas durante o governo Lula que permitiram forte inclusão de negros em ambientes educacionais e políticos. Entretanto, a pressão social de pessoas que se sentem ameaçadas em seu privilégio provoca um discurso oficial de se averiguar a verdadeira negritude dos beneficiados pelas cotas, afim de assegurar a correta aplicação destas. Ocorre que, o negro brasileiro tem sua identidade marcada pela mestiçagem e pela assimilação cultural, mais fortemente sentida por aqueles que possuem coloração negra mais clara ou ocupam lugares sociais mais elevados.

$\mathrm{O}$ perigo de se ignorar essa realidade peculiar revela a necessidade de se definir o grupo minoritário negro, para que haja uma resposta a intenção de se auferir negritude com base em dados biológicos; essa resposta deve abarcar toda a realidade social no qual os negros brasileiros foram e estão inseridos.

\subsection{Objetivo e Metodologia}

A partir dessa compreensão, o objetivo desse artigo é apontar que o elemento comum a esses negros é a discriminação racial, especialmente em território brasileiro e com todas as peculiaridades a este implicadas. Em análise plural que possa demonstrar o fenômeno em sua realidade multifacetada e trazer a voz negra para o debate científico que propõe a defini-los.

A metodologia adotada na pesquisa consiste em pesquisa bibliográfica, incluindo livros, revistas científicas, reportagens, leis, jurisprudências, assim como a devida análise de dados e relatórios.

\section{MINORIA NEGRA NO BRASIL E A DISCRIMINAÇÃO.}

Quando se aplica a discussão acerca da necessidade de conceituar os grupos minoritários, com o fim de que as políticas destinadas a esses grupos tenham a devida eficácia na redução das desigualdades, aos negros no Brasil, essa discussão deve necessariamente perpassar o conceito de raça; conceito que se apresenta em nosso território sob forma peculiar e com o elemento 'cor' figurando apenas como um dos elementos identificadores. 


\subsection{Contexto brasileiro: miscigenação.}

No século XIX surgem diversas correntes filiadas a um darwinismo racial que passam a relacionar elementos corporais, fenótipos, a condições definidores dos indivíduos enquanto seres que estariam para trás na evolução das espécies. Dessa forma, o conceito de raça foi criado com objetivo de definir esses grupos identificáveis a partir dessas características externas e legitimar as desigualdades provenientes de um passado escravagista com fundamentos biológicos (SCHWARCZ, 2012).

O contexto social brasileiro no século XIX é composto pela pluralidade de cores, aqui os índios, negros e brancos compõem a identidade brasileira a partir da miscigenação, a mistura de cores de diferentes povos é uma importante característica dos brasileiros e o debate sobre negros implica diretamente em falar sobre a miscigenação.

Os teóricos do darwinismo racial enxergavam miscigenação enquanto degeneração, a mistura de raças, para esses teóricos implicariam em resultados inferiores às duas raças tidas como originais. No Brasil, a importação da teoria evolucionista se separa desse darwinismo racial, aqui a miscigenação passa a ser encarada como fator positivo: garante o embranquecimento da população.

Foi com esse discurso que o Brasil apresentou no I Congresso Internacional das Raças em 1911 que em um século a população brasileira seria completamente branca, a miscigenação seria apenas uma etapa desse projeto maior, que em um século garantiria a extinção da população negra, indígena e mestiça; com forte incentivo a vinda de imigrantes europeus ou apenas brancos. Por mais inverossímil que pareça escutar que esse discurso de fato existiu, vale ressaltar que a recepção, no dito congresso, não foi positiva: um século seria tempo demais para o embranquecimento completo, e apenas este poderia garantir o desenvolvimento e a liberdade de qualquer nação (SCHWARCZ, 2012).

Com essa tentativa radical de se embranquecer a população recebida negativamente, a partir de 1930 o Brasil adota a postura de assumir feição da miscigenação enquanto símbolo da identidade brasileira, com esse discurso formal de aceitação da miscigenação enquanto realidade brasileira e não apenas enquanto uma etapa de um processo, o Estado não adota qualquer medida que promova a inclusão dos povos negros e mestiços. O discurso formal se separa da realidade social, que adotou enquanto cultura a discriminação e a desvalorização 
(OLIVEIRA, 2004) dos povos negros enquanto indivíduos merecedores dos mesmos direitos e proteção.

\subsection{Raça enquanto construção social}

Justamente com o reconhecimento desses fundamentos biológicos de raça enquanto definidor de hierarquias sociais, se faz necessária a compreensão da raça enquanto construção social. Os fundamentos biológicos se mostraram vazios e cruéis, ignoravam completamente a subjetividade e unicidade de cada indivíduo e a riqueza cultural que provém das diferenças. No entanto, como essas hierarquias e discriminação permanecem só se tornam possível com a análise de raça enquanto construção social, com toda a naturalização que permeou e travestiuse de cultura, naturalizando e compondo os imaginários individuais e coletivos.

Os esforços intelectuais passaram a demonstrar o que realmente representava a categoria de raça definida biologicamente. Nos anos de 1947, 1951 e 1964 a UNESCO financiou reuniões para que 'raça' passasse a ser uma definição utilizada para classificarmos as pessoas em grupo tão somente a partir da observação, classificação que daria uma conotação de naturalidade às organizações sociais baseadas na desigualdade, exclusão e exploração de indivíduos sobre outros. Com essa desnaturalização da raça, no entanto, não se desfez o marcador social que a classificação criou, a raça ainda legitima o espaço da discriminação.

No Brasil, o que ocorreu com o discurso formal de igualdade e exaltação da identidade miscigenada, negra, não foi a eliminação da desigualdade no plano material, nas relações sociais, mas uma postura de cultura assimilacionista que apenas se coloca de forma passiva às desigualdades que se apresentam em simples análise estatística. A identidade negra apenas servia ao discurso de um Brasil plural e harmônico, mas a realidade social tenta eliminar e expurgar quaisquer sinais que remetam à cultura e identidade negras; a igualdade cega retira o direito do negro à sua própria identidade, enquanto o massacra por não ser branco.

Em 1951 um dos projetos financiados pela UNESCO pretendia exaltar a aparente sociedade harmônica que convive com a mestiçagem, mas os estudos capitaneados por, dentre outros, Florestan Fernandes e Roger Bastide, mostraram um Brasil permeado pela discriminação e preconceito, demonstrando que a aparente tolerância racial representava apenas um "certo código de decoro que, na prática, funcionava como um fosso intransponível entre os diferentes grupos sociais" (SCHWARCZ, 2012, p. 70). 
Essas análises também deflagraram o preconceito que se apresenta no Brasil de forma velada, o brasileiro, arraigado em seus valores morais cristãos não admite reconhecer o preconceito, apenas o pratica em ações dissimuladas de tradição e costumes. O próprio discurso que surge a partir de uma abolição que se deu com um aparente aval de bondade da coroa portuguesa, tenta redefinir o passado de escravidão com uma aura de paternalismo e boa vontade por parte dos escravos. Uma tentativa de aliviar a crueldade que não se apaga desse passado.

A forma como esse discurso se alivia, entretanto, contribui mais fortemente para que os negros continuem sendo vistos como subalternos inveterados. A naturalização de uma ordem opressora e de dominação combinada à designação das classes inferiores enquanto uma classe predominantemente negra.

Esses elementos emplacados em contexto de sociedade miscigenada permite que a cor aqui seja um elemento de negociação, o indivíduo enegrece ou embranquece de acordo com o status quo que ocupa, de acordo com o poder aquisitivo. $\mathrm{O}$ negro brasileiro tem um lugar social demarcado, as pessoas que fogem a esse lugar social dificilmente fugirão ao racismo, que se apresentará, entretanto, de forma diferenciada; vez que aqueles que ascendem à lugares brancos, dificilmente poderão ter sua identidade negra reconhecida.

Nesse contexto, a ideia de raça enquanto construção social nos permite ver que, no Brasil, a raça negra está necessariamente associada à cor da pele e às classes mais pobres. A naturalização dessa desigualdade muitas vezes se disfarça sob o manto das aptidões, gostos, dons. Ao se analisar os dados, entretanto, percebe-se que, no momento em que a maioria esmagadora de indivíduos, que de semelhança compartilham apenas a cor de pele e o estigma social, ocupam os mesmos postos de trabalho não há como enxergar isso como opção, mas sim como um condicionamento social engendrado.

Para elucidar melhor a perspectiva de raça enquanto construção social e a imprescindibilidade desta compreensão para uma proteção jurídica efetiva e promoção satisfatória de uma democracia racial, vale o aprofundamento da discriminação racial, nos moldes nos quais ocorre no Brasil, a importância de seu reconhecimento é o primeiro passo.

\subsection{Discriminação racial}

A discriminação, de fato, não é um fenômeno atrelado somente ao grupo minoritário identificado como negros, podendo ser referente à diferentes religiões, classes sociais, gênero, 
sexualidades e funcionalidades do corpo. No entanto, em relação aos negros a discriminação possui uma faceta peculiar, histórica, cultural e, assim como a performatividade do gênero, diz respeito a características externas; são discriminações que antecedem qualquer tipo de contato e, muitas vezes, pode anteceder a própria razão de quem discrimina; fator que de maneira nenhuma atenua a responsabilidade de estarmos atentos aos próprios preconceitos e tendências, mas, exatamente por ser dessa forma, merece uma atenção e cuidado reforçados.

Em coaduno com Barbosa (2001), discriminação pode ser definida como uma forma de criar diferenças, uma espécie de ficção que tem participação intelectual ativa e, muitas vezes, muito bem desenvolvidas, ainda que dentro de seus erros, com a finalidade de legitimar agressões e privilégios.

Perceber as particularidades dos negros brasileiros implica a constatação, conforme já trabalhado no artigo, de que o fenótipo não representa um fator absoluto para conceituar esse grupo. O renascimento de fundamentos biológicos desse tipo representa grande ameaça ao real objetivo de combater a desigualdade atrelada à figura dos negros no Brasil. O país que é reconhecido globalmente por sua forte miscigenação não pode deixar esse elemento em paralelo a essas discussões, aqui podemos identificar o grupo merecedor da proteção jurídica, enquanto grupo minoritário, com base na discriminação racial, ao se compreender a raça com todas as sutilezas históricas deste país.

A primeira peculiaridade da discriminação racial -usarei racismo como sinônimo- no Brasil pode ser traduzida no 'preconceito de ter preconceito', conforme foi levemente exemplificado no ponto acerca da miscigenação, as pessoas assumem uma postura de decoro, de harmonia, principalmente em espaços públicos; os quais, muitas vezes, são inclusive condecorados com os artigos constitucionais que repudiam o racismo. Diferente de países como os Estados Unidos e a África do Sul, não tivemos no Brasil um histórico de segregação racial adotada enquanto política de Estado. Em sentido contrário, o governo sempre adotou um discurso formal de igualdade.

No entanto, os dados não mais deixam que as realidades sociais sejam ignoradas. É muito comum que, ao ouvir tais discursos oficiais, as pessoas que ocupam posição privilegiada continuem confortáveis em suas posições opressoras, e, dessa forma, a estrutura de uma sociedade hierarquizada, de um país rico com muitos pobres, seja ativamente mantida dessa forma. Nesse sentido, porém, a globalização acumula pontos positivos, as informações estão circulando cada vez mais e a oportunidade de voz aparece para muitos pela primeira vez. 
Em relação ao ato de discriminar, em pesquisa realizada em 1995 pela Folha de São Paulo (SCHWARCZ, 2012) 89\% dos brasileiros disseram que há racismo no Brasil; apenas $10 \%$ admite tê-lo, enquanto que de maneira indireta, ou seja, não reconhecida, $87 \%$ revelaram preconceitos em suas falas. Quanto aos resultados da discriminação, ou a discriminação que podemos quantificar por estarem imprimidas em condições objetivas da população negra, os dados se mostram alarmantes em todas as esferas.

De acordo com pesquisa realizada por Rosenberg (1990) a diferença entre réus negros e brancos eram bem definidas, desde a dificuldade do acesso à justiça criminal, passava pela dificuldade maior de um réu negro em ter seu direito de ampla defesa respeitado e, por fim, a probabilidade de ser punido mais rigorosamente se mostrava significativamente maior em comparado aos réus brancos. Em se tratando da educação formal e, considerando a forte precarização do ensino básico da rede pública, é simbólico que, ainda em pesquisas de referida autora, o ensino básico das instituições públicas de São Paulo fosse em 1982 representasse $97,1 \%$ da população negra em comparação aos $89 \%$ da população branca. Conforme demonstrado por Barcelos (1993) a população branca possui um nível de escolaridade em média duas vezes maior em relação a população não branca - os brancos teriam uma média de quatro anos de escolaridade, enquanto que para o restante a média chega a dois anos.

Um infográfico elaborado pelo veículo independente Rede Angola (2014, online) demonstra que, ainda que a população brasileira seja declaradamente constituída em 50,4\% por negros, a porcentagem dessa população nas universidades era referente à $26 \%$ da totalidade dos universitários, resultado alcançado somente com o implemento de políticas sociais afirmativas que, atualmente, garantem cinquenta por cento das vagas universitárias aos negros -dentre outros requisitos sociais a serem observados-. O estudo mais recente localizado para substrato do presente artigo referente ao percentual de professores negros nas universidades no Brasil foi realizado em 2004 e apresenta o dado alarmante de não chegar a 1\% o número de professores negros na Universidade; em um total de 4,7 mil professores da Universidade de São Paulo, o número de professores negros não chegava a dez. O ambiente acadêmico, em níveis de pósgraduação, demonstra cada vez mais fortemente não ser um ambiente pensado, ainda hoje, para negros.

Os dados recentes de pesquisas e relatórios internacionais não permitem mais ignorarse que as políticas que combatem a discriminação em solo brasileiro devem ser fortalecidas, é necessário forte posicionamento em sentido de não retroceder combinado a uma aproximação do debate e da realidade de marginalização da população negra em território brasileiro. $\mathrm{O}$ 
Conselho de Direitos humanos da ONU (2016) elaborou relatório a respeito das minorias no Brasil, com base em visita feita em 2015, a visitante encarregada pelo relatório observou que a discriminação enraizada no discurso brasileiro de aparente harmonia racial provoca forte marginalização da população negra, avaliando que os avanços na temática ainda não se mostram suficientes.

O relatório (ONU, 2016) faz referências à criminalização da população negra, violência e abusos policiais direcionados a população negra, ocupação dessa população em áreas com precária infraestrutura e educação; falta de representatividade de negros em posições de autoridades; a situação dos quilombolas e o desrespeito às religiões de matriz africanas.

Incorrendo em assuntos ainda polêmicos quando da discussão dentro do País, e em nível de políticas públicas ou discursos oficiais, os dados são alarmantes: em 2013 66,7\% das mortes de mulheres eram referentes à mulheres e garotas negras. Em estudo do IPEA (2011) em 2009 65,5\% das mulheres como 16 anos ou mais tinham o mínimo de nove anos de estudo, no universo de mulheres negras a porcentagem se reduz a 48,7\%. A taxa de mulheres brancas no ensino superior é de 23,8\%, para mulheres negras a taxa era de 9,9\%. Em 2006, 70\% das famílias beneficiadas pelo Bolsa família eram famílias chefiadas por negros. A maior taxa de desemprego é atualmente a taxa referente às mulheres negras, em somando $12 \%$ de desemprego, ao passo em que a taxa entre homens brancos é $5 \%$, homens negros $7 \%$, e mulheres brancas $9 \%$.

Dentro do universo de mulheres brasileiras empregadas, são $17,1 \%$ as mulheres empregadas em trabalho doméstico, em contraponto à $1 \%$ desses trabalhadores dentre os homens. Da parcela de mulheres brancas são $12,6 \%$ as que se dedicam ao trabalho doméstico, as mulheres negras, por sua vez, dedicam-se em percentual quase dobrado de 21,8\%. Em 2009 os negros participavam em $72 \%$ dos $10 \%$ mais pobres da população brasileira.

No Rio de Janeiro $80 \%$ das vítimas de homicídios decorrentes de abusos policiais são negros, $75 \%$ da população carcerária é composta por negros; dentro desse contexto o fato de que em 220 casos de homicídios por policiais investigados apenas um ter sido condenado, demonstra a falta de pressão política e a distância da população em geral da criminalização e exclusão da população negra (ONU, 2016, online).

Com dados como estes, fica cada vez mais difícil de não se reconhecer o racismo latente e a nítida exclusão da população negra. Se a lei já designa a proibição do racismo exposto em ambientes públicos e de maneira que possa ser comprovada, o racismo continua a corroer 
no ambiente do privado; ambiente de difícil inserção do direito, que envolve mudanças sociais, culturais e importantes doses de posturas autocríticas. Porém, esse debate merece um aprofundamento devido que poderá ser feito em um outro momento.

O que deve ser frisado, ao propor que se conceitue o grupo minoritário de negros no Brasil a partir do elemento discriminação, é a compreensão desta em todas as esferas da identidade dos indivíduos negros, que, desde a mais tenra infância carregam a dor no peito que, os poucos que possuem o privilégio de poderem dedicar-se aos estudos, conseguem ao decorrer da vida nomear e reconhecer a dor enquanto uma discriminação que pertence aos outros; mas durante esse processo difícil e demorado o não reconhecimento dessa discriminação assume uma potência que domina os indivíduos e os diminuem.

A obra de Beatriz Nascimento, mulher negra, acadêmica e nordestina, recentemente resgatada e analisada (RATTS, 2006) traz em diversos momentos essa relação conflituosa que se dá no interior da individualidade dos negros, por não ter a exata noção do que ocorre ao ser discriminado; pois, quando a discriminação é dissimulado, a tendência é que as pessoas que sofrem a discriminação também demorem- ou nunca cheguem a - a entender ou reconhecer a existência dessa discriminação ${ }^{3}$.

A linguagem científica não se comunica aos nossos sentidos da mesma forma que um relato, por esse motivo, para melhor ilustrar e, com fins didáticos, demonstrar o sentimento de quem sofre racismo trago trechos da obra resgatada de Beatriz Nascimento por Ratts (2006), p.47:

\begin{abstract}
A todo momento o preconceito racial é demonstrado diante de nós, é sentido. [...] De certa forma, algumas dessas manifestações já foram incorporadas como parte da nossa. [...] De tal forma que o preconceito contra o negro é violento e ao mesmo tempo sutil, que ele existe latente e muitas vezes vem à tona na relação entre nós mesmos. Temos, vamos dizer, uma atitude de amor e ódio por nós mesmos; a presença, o confronto com o outro nos incomoda também.

$[\ldots]$

Observando bem, a gente chega numa conclusão que vive numa sociedade dupla ou tripla. Na medida em que ela impõe na sua cabeça que é uma sociedade branca, que o seu comportamento tem que ser padronizado segundo os ditames brancos, você como preto se anula, passa a viver uma outra vida, flutua sem uma base onde possa pousar, sem referência e sem parâmetro do que deveria ser a sua forma peculia.
\end{abstract}

\footnotetext{
${ }^{3}$ Schwarcz (2012,p. 99) cita estudo de João Batista Felix que observou que "a maioria dos entrevistados negou ter sido vítima de discriminação, porém confirmou casos de racismo sofridos por familiares e conhecidos próximos."
} 
A força desse relato demonstra não somente o racismo que ao ser dissimulado tornase mais poderoso, e encontra guarida dentro dos próprios indivíduos pertencentes à minoria negra, em clara tendência desmobilizadora; mas ainda, o racismo que se apresenta às poucas pessoas que fogem à regra e ocupam lugares privilegiados na sociedade, aqueles que acabam contribuindo para a aparente harmonia racial.

Essa forma de discriminação é sentida por uma prática assimilacionista, significando que a harmonização racial depende que o negro abra mão de sua identidade de negro para se integrar à cultura hegemônica que legitima uma superioridade branca. Acerca da identidade, é importante saber que atualmente em contextos multiculturais em escala global a importância do respeito às diferenças, que devem ser reforçadas em medidas que contribuam para a plena realização do indivíduo, é tema de diversas pesquisas e se configura um entendimento unânime: as diferenças devem ser eliminadas tão somente em relação ao tratamento que dificulta o acesso a direitos e oportunidades.

Gomes (2001) é contundente ao analisar o pensamento de Charles Taylor e demonstrar a importância da imagem da coletividade para as formações de identidades pessoais, e, dessa forma, o reconhecimento das diferentes identidades e culturas não pode ser considerado qualquer 'cortesia', mas um dever que deriva e protege a própria dignidade da pessoa humana, princípio que norteia os ordenamentos jurídicos democráticos.

A desvalorização ou desconsideração da intelectualidade negra (OLIVEIRA, 2014) representa mais uma importante faceta da discriminação racial. Se o direito formal preconiza a igualdade entre as diferentes etnias, poderia se considerar por finda a descriminação a nível intelectual. Porém, não é o que ocorre.

Popper (2010) há muito já havia atentado para a cautela que devemos ter em relação às nossas concepções. Estamos todos, enquanto seres humanos condicionados a incorrer em erros, todo conhecimento que produzimos será eivado em alguma medida pelos valores que carregamos, provenientes de nossa formação individual. Chamada teoria falibilista, tem como objetivo destacar a importância do investigador em assumir postura crítica em relação às próprias ideias, essa consiste na única forma de se buscar verdadeiramente o conhecimento.

Compreendendo a natureza humana por essa concepção falibilista, se torna mais clara a compreensão da carga histórica e cultural que todos os seres humanos carregam. Essa carga histórica pende, excessivamente, para a desvalorização do intelecto negro. A classe associada ao trabalho braçal, ao corpo, à sexualidade, à capoeira, não costuma ser facilmente associada à 
atividade intelectual. As desvalorizações combinadas à dificuldade objetiva de acesso aos ambientes intelectuais constroem juntas um forte bloco discriminatório.

Os negros que não possuem fácil acesso, dificilmente chegam sequer a almejar a ascensão social; os que almejam encontrarão toda sorte de obstáculos objetivos e a forte descrença dos que os rodeiam; aqueles que possuem privilégios oriundos da ascensão social de seus antecessores conhecerão por toda a vida o sentimento de solidão e isolamento.

Sobre o sentimento de solidão, novamente a força do relato de Beatriz Nascimento (RATTS, 2006, pp. 48-49) faz-se oportuno:

Esse processo costuma ser longo e insidioso e começa já na escola primária. Lá em Sergipe, para citar um fato concreto. Eu estudava numa escola que era num terreno arrendado de minha avó, era em frente à casa dela; pois bem, eu muitas vezes inventava uma dor de barriga e fugia, sabe por quê? Porque tinha pouquíssimas crianças negras iguais a mim na escola. E esse fenômeno acontece comigo até hoje. Eu me sinto mal, me dá uma sensação de isolamento quando eu estou num grupo onde não tem muitos pretos.

$[\ldots]$

É aquela mecânica de educação que não tem nada a ver com esses grupos de educação familiar, a mecânica da leitura, onde você não sabe quem é, porque não está nos livros. [...]

Quando eu comecei a mergulhar dentro de mim, como negra, foi justamente na escola que era um ambiente em que eu convivia com a agressão pura e simples, com o isolamento, com as interpretações errôneas, estupidas das professoreas, a ausência das pessoas da minha cor na sala de aula, a falta de referência.

$[\ldots]$

No meu interior há recalcamento das aspirações mais simples. Em contato com as outras pessoas tenho que dar praticamente todo o meu 'curriculum vitae' para ser um pouquinho respeitada. [...] Quando de volta ao cotidiano, verifico que as pessoas veem a minha cor como meu principal dado de identificação, e nesta medida tratam-me como um ser inferior.

A importância dos relatos em trabalhos acadêmicos se consubstancia justamente na necessidade de se fazer um espaço que ecoe também a voz negra. Considerando a discriminação como uma 'rede' que atua em esferas objetivas, mas também em esferas mais complexas, ambientes íntimos, relações travadas em esfera pessoal, mas que não devem ser renegadas à preocupação em nível interpessoal. 


\section{CONSIDERAÇÕES FINAIS}

A partir do momento que essas discriminações surgem de maneira hegemônica e resultam em dados que condicionam a realidade objetiva da população negra e que proporciona cor à desigualdade na realidade brasileira, esse racismo deve ser percebido tal como é, como uma realidade estrutural e institucionalizada. Nessa medida que a discriminação racial, se torna um elemento definidor de um grupo minoritário.

Essa discriminação não consiste em preconceitos subjetivos e pontuais, os quais geralmente devem ser tratados em esferas pessoais; mas a proporção estrutural demonstra uma prática de toda uma sociedade que continua por promover a exclusão de um grupo que se identifica por um demarcador social fictício que, historicamente, serviu para legitimar a hierarquização social e a dominação de grupos sobre outros.

Dessa forma, apesar de todas as divergências doutrinárias quanto à conceituação de grupos minoritários, a importância de uma conceituação torna mais aceitáveis, ao restante da população, as políticas destinadas à inclusão e redução de desigualdades e assegura em certa medida a correta aplicação dessas políticas, por facilitar um controle externo. No entanto, a definição deve levar em consideração a formação do grupo minoritário no território ao qual se delimita para abarcar as sutilezas e promover, de fato uma mudança cultural e social.

\section{REFERÊNCIAS}

BARCELOS, L. C. Educação- um quadro das desigualdades raciais. In: Estudos AfroAsiáticos, Rio de Janeiro: Centro de Estudos Afro-Asiáticos, 1993, n. 23, pp.45-6.

GOMES, Joaquim B. Barbosa. Ação afirmativa \&; princípio constitucional da igualdade (O Direito como instrumento de transformação social. A experiência dos EUA). Rio de Janeiro: Renovar, 2001.

IPEA, Instituto de Pesquisa Econômica Aplicada. Retrato das desigualdades de gênero e raça. $4^{\mathrm{a}}$ ed. Brasília, 2011: Ipea.

ROSENBERG, Fulvia. Segregação espacial na escola paulista. In: Estudos Afro-Asiáticos, Rio de Janeiro: Centro de Estudos Afro-Asiáticos, 1990, n.19, pp. 100-3.

OLIVEIRA, Luís R. Cardoso de. Racismo, direitos e cidadania. Estud. av. 2004, online, vol.18, n.50, pp.81-93. ISSN 0103-4014. http://dx.doi.org/10.1590/S0103-

40142004000100009. Acesso em 10 de agosto 2017 
ONU, Organização das Nações Unidas. Report of the Special Rapporteur on minority issues on her mission to Brazil. 2016, online. Disponível em: $<$ https://documents-ddsny.un.org/doc/UNDOC/GEN/G16/021/35/PDF/G1602135.pdf?OpenElement> Acesso em: $10 \mathrm{de}$ agosto 2017.

POPPER, Karl. Falsificacionismo versus convencionalismo. In: MILLER, David (Org.). Popper: textos escolhidos. Tradução de Vera Ribeiro. Rio de Janeiro: Contraponto, 2010, p.141148.

RATTS, Alex. Eu sou atlântica: sobre a trajetória de vida de Beatriz Nascimento. São Paulo: Imprensa oficial, 2006.

RODRIGUES, Antonio. Retrato dos negros no Brasil. 2014, online. Disponível em:< http://www.redeangola.info/multimedia/retrato-dos-negros-no-brasil/> Acesso em $10 \mathrm{de}$ agosto 2017.

SCHWARCZ, Lilia Moritz. Racismo no Brasil: quando inclusão combina com exclusão. P. 94-107. In: SCHWARCZ, Lilia Moritz; BOTELHO, André. (Org.). Cidadania, um projeto em construção: minorias, justiça e direito. São Paulo: Claro Enigma, 2012.

Nem Preto Nem Branco, muito pelo contrário: cor e raça na sociabilidade brasileira. São Paulo: Claro Enigma, 2012.

MOLINA, Sandra Cordeiro. Raça, Direito e Políticas Públicas para a Promoção da Igualdade Racial no Brasil: Alguns apontamentos. P. 435- 455. In: SMANIO, Gianpaolo Poggio; BERTOLIN, Patrícia Tuma Martins. (Org.). O Direito e as Políticas Públicas no Brasil. São Paulo: Ed. Atlas, 2013.

NUSSBAUM, Martha C. Sem fins lucrativos: porque a democracia precisa das humanidades. São Paulo: Ed. WMF Martins Fontes, 2015. 